\title{
Contribuições da assistência de enfermagem na prevenção de lesões de pele em recém-nascidos na Unidade de Terapia Intensiva Neonatal
}

Contributions of nursing care in the prevention of skin lesions in newborns in the Neonatal Intensive Care Unit

Contribuciones de los cuidados de enfermería en la prevención de lesiones cutáneas en recién nacidos en la Unidad de Cuidados Intensivos Neonatales

Mariana Pereira Barbosa Silva ORCID: https://orcid.org/0000-0003-0852-8099 Universidade Estadual do Piauí, Brasil E-mail: marianapbsilvaa@gmail.com

Rayssa Stéfani Sousa Alves ORCID: https://orcid.org/0000-0002-9666-675X Pontifícia Universidade Católica de Goiás, Brasil E-mail: rayssastefani02@gmail.com

Marciele de Lima Silva

ORCID: https://orcid.org/0000-0003-2827-5316 Instituto de Educação Superior da Paraíba, Brasil E-mail: marcieledelsilva@gmail.com

Danielle Sousa Almeida

ORCID: https://orcid.org/0000-0002-0537-8972

Centro Universitário Santo Agostinho, Brasil E-mail: daniellyalmeida99@gmail.com

Lorena Mayara Hipólito Feitosa ORCID: https://orcid.org/0000-0002-3643-3436 Universidade Federal do Piaú, Brasil E-mail: lorena_mayara@hotmail.com

Juliana Torres Avelino

ORCID: https://orcid.org/0000-0002-8732-1856

Centro Universitário Santo Agostinho, Brasil E-mail: Juliana_avelinno@hotmail.com

Clênio Oliveira Barrense

ORCID: https://orcid.org/0000-0003-1457-1317 Universidade Estadual do Piauí, Brasil E-mail: cleniobarrense@yahoo.com.br

Bárbara Pereira Gomes

ORCID: https://orcid.org/0000-0002-0590-2228 Centro Universitário Unifacid, Brasil E-mail: barbaraenfgomes@gmail.com

Maria da Conceição Silva Castro Sousa ORCID: https://orcid.org/0000-0002-6222-6270

Centro Universitário Santo Agostinho, Brasil E-mail: maria.castro0013@outlook.com Álesson Marlon Silva da Luz ORCID: https://orcid.org/0000-0002-2684-3669 Centro Universitário Maurício de Nassau, Brasil E-mail: allesson.luz@gmail.com

Ingrid Ruanna Ximenes e Sousa ORCID: https://orcid.org/0000-0001-7529-155X Centro Universitário Santo Agostinho, Brasil E-mail: ingridxims30@gmail.com

Allan Bruno Alves de Sousa Santos ORCID: https://orcid.org/0000-0001-6412-7164 Faculdade de Educação São Francisco, Brasil E-mail: abass@faesf.com.br 
Laiana Dias Prudêncio

ORCID: https://orcid.org/0000-0002-0016-3868 Centro Universitário Maurício de Nassau, Brasil E-mail: laianadias568@gmail.com

Márcia Bethania de Sousa Silva

ORCID: https://orcid.org/0000-0001-5059-7528

Centro Universitário Santo Agostinho, Brasil

E-mail: marcia-bethania@hotmail.com

Adriele Dantas do Val Silva

ORCID: https://orcid.org/0000-0001-9727-7783

Centro Universitário Santo Agostinho, Brasil

E-mail:adrieledovale@gmail.com

Suzane Sales Oliveira

ORCID: https://orcid.org/0000-0002-8112-4640

Centro Universitário Santo Agostinho, Brasil

E-mail: suzanesaless@gmail.com

Rihama Layla Rodrigues Costa

ORCID: https://orcid.org/0000-0001-9537-7561

Centro Universitário Maurício de Nassau, Brasil

E-mail: rihamah_costa@hotmail.com

Ingrid Tainá Sousa Dias

ORCID: https://orcid.org/0000-0002-0306-3838 Centro Universitário Maurício de Nassau, Brasil

E-mail: ingrid_tdias@outlook.com

Laísa Ribeiro Rocha

ORCID: https://orcid.org/0000-0002-8147-8342

Centro Universitário Unifacid, Brasil

E-mail: laisaribrocha@gmail.com

Eduarda Beatriz Reis Paz

ORCID: https://orcid.org/0000-0003-2910-6928

Centro Universitário do Estado do Pará, Brasil

E-mail: reispaze@gmail.com

Jeferson Moreira dos Santos

ORCID: https://orcid.org/0000-0001-7807-1341

Universidade do Estado da Bahia, Brasil

E-mail: Jeff.ibce73@gmail.com

Samara Atanielly Rocha

ORCID: https://orcid.org/0000-0002-5622-9280

Faculdade de Saúde e Humanidades Ibituruna, Brasil

E-mail: samaraatanielly@outlook.com

Thyago de Oliveira Afonso

ORCID: https://orcid.org/0000-0001-7616-9011

Universidade Federal de Pernambuco, Brasil

E-mail: thyago.afonso@ufpe.br

\section{Resumo}

Analisar as evidências científicas sobre os cuidados de enfermagem na prevenção de lesões de pele em recémnascidos na Unidade de Terapia Intensiva Neonatal. O presente estudo trata de uma revisão bibliográfica do método revisão integrativa da literatura, realizado nos meses entre agosto e dezembro de 2020. A busca efetuou-se, através da Plataforma - BVS, utilizando as bases de dados (LILACS), (BDENF), (MEDLINE), (IBECS), e por meio do Portal Google Acadêmico, aderindo-se através dos descritores/palavras chaves: "Recém-nascido", "Unidades de Terapia Intensiva Neonatal", "Cuidados de Enfermagem", "Desenluvamentos Cutâneos", cruzados com o operador booleando "OR" e posteriormente combinados com o operador booleano "AND". Compreende-se que o cuidado com a pele do recém-nascido é um processo amplo, que exige cientificidade, responsabilidade, comprometimento, carinho e dedicação por parte da equipe de enfermagem. Desta forma, reforça-se a afirmação de que o cuidado com a pele “é uma intervenção de enfermagem de forma contínua, dinâmica, eficaz, individualizada, criteriosa e humanizada, visando à promoção, manutenção ou recuperação da integridade da pele do recém-nascido, considerando os aspectos fisiológicos, ambientais e da assistência". É necessário buscar na assistência de enfermagem em Unidade de Terapia Intensiva Neonatal, pela sua alta complexidade em atendimentos, desenvolver métodos de trabalhos relacionados ao cuidado com a pele dos recém-nascidos, que proporcione uma prática de enfermagem unificada, evidente, com metas a curto e longo prazo, favorecendo e explicitando a eficácia das atividades desenvolvidas.

Palavras-chave: Recém-nascido; Unidades de Terapia Intensiva Neonatal; Cuidados de enfermagem; Desenluvamentos cutâneos.

\section{Abstract}

To analyze the scientific evidence on nursing care in the prevention of skin lesions in newborns in the Neonatal Intensive Care Unit. The present study deals with a bibliographic review of the integrative literature review method, carried out between August and December 2020. The search was carried out, through the Platform - VHL, using the 
databases (LILACS), (BDENF), (MEDLINE), (IBECS), and through the Google Scholar Portal, adhering through the descriptors / keywords: "Newborn", "Neonatal Intensive Care Units", "Nursing Care", "Cutaneous Development", crossed with the Boolean operator "OR" and later combined with the Boolean operator "AND". It is understood that the newborn's skin care is a broad process, which requires scientificity, responsibility, commitment, affection and dedication on the part of the nursing team. Thus, it is reinforced the statement that skin care "is a continuous, dynamic, effective, individualized, careful and humanized nursing intervention, aiming at the promotion, maintenance or recovery of the newborn's skin integrity , considering the physiological, environmental and assistance aspects ". It is necessary to seek nursing care in the Neonatal Intensive Care Unit, due to its high complexity in care, to develop work methods related to newborn skin care, which provides a clear, unified nursing practice with short-term goals. and long term, favoring and explaining the effectiveness of the activities developed.

Keywords: Newborn; Neonatal Intensive Care Units; Nursing care; Skin development.

\section{Resumen}

Analizar la evidencia científica sobre cuidados de enfermería en la prevención de lesiones cutáneas en recién nacidos en la Unidad de Cuidados Intensivos Neonatales. El presente estudio trata de una revisión bibliográfica del método de revisión integradora de la literatura, realizada entre agosto y diciembre de 2020. La búsqueda se realizó, a través de la Plataforma - BVS, utilizando las bases de datos (LILACS), (BDENF), (MEDLINE), (IBECS), ya través del Portal Académico de Google, adhiriéndose a través de los descriptores / palabras clave: "Recién Nacido", "Unidades de Cuidados Intensivos Neonatales", "Cuidados de Enfermería", "Desarrollo Cutáneo", cruzados con el operador booleano "OR" y posteriormente combinados con el operador booleano "Y". Se entiende que el cuidado de la piel del recién nacido es un proceso amplio, que requiere cientificidad, responsabilidad, compromiso, cariño y dedicación por parte del equipo de enfermería. Así, se refuerza la afirmación de que el cuidado de la piel "es una intervención de enfermería continua, dinámica, eficaz, individualizada, cuidadosa y humanizada, que tiene como objetivo la promoción, mantenimiento o recuperación de la integridad de la piel del recién nacido, considerando los aspectos fisiológicos, ambientales y asistenciales". . Es necesario buscar atención de enfermería en la Unidad de Cuidados Intensivos Neonatales, debido a su alta complejidad en el cuidado, para desarrollar métodos de trabajo relacionados con el cuidado de la piel del recién nacido, que brinde una práctica de enfermería clara, unificada con metas a corto y largo plazo, favoreciendo y explicando la efectividad de las actividades desarrolladas.

Palabras clave: Recién nacido; Unidades de Cuidados Intensivos Neonatales; Cuidado de enfermera; Desarrollo de la piel.

\section{Introdução}

A pele é o maior órgão do corpo humano e desenvolve múltiplas funções, incluindo a barreira contra perda de água e agressão a irritantes, termorregulação, controle de infecção, imunovigilância e sensação tátil. As camadas principais da pele são a epiderme, a derme e a hipoderme. A camada mais superficial da pele reside na epiderme e chama-se estrato córneo, sendo a principal barreira para perda de água e penetração de agentes externos (Santos, \& Costa, 2015).

Como o maior órgão do corpo humano, a pele forma uma barreira entre os órgãos internos e o ambiente externo proporcionando uma proteção contra invasões ao organismo. Considerando a diferença de sensibilidade da pele nas suas várias fases evolutivas, a pele infantil é mais frágil e vulnerável em relação à pele do adulto. A pele do recém-nascido (RN) apresenta particularidades que devem ser conhecidas pelos profissionais de saúde; estas diferem de acordo com a raça e com a idade gestacional (Sousa et al., 2011).

De acordo com Severo et al. (2020), a pele do neonato é de superfície constante, pouco espessa, crítica, delicada e danifica com facilidade. Mesmo a estrutura sendo semelhante à pele do adulto, ela possui muitas funções que não estão completamente desenvolvidas que apresentam maior sensibilidade a irritantes químicos e permeabilidade a agentes tóxicos, estando suscetível ao aparecimento de lesões como resposta aos mínimos traumas.

As lesões por pressão (LPP) são definidas como lesões superficiais ou profundas, que ocorrem devido à falta de oxigênio e/ou nutrientes em uma determinada área para suprir as necessidades dos tecidos, sendo desencadeadas pela pressão exercida sobre o tecido. Os pacientes acometidos a uma determinada patologia e que necessitam ficar imobilizados por um tempo maior, apresentam um aumento no risco de desenvolvimento de outras complicações, estabelecendo um sério problema de saúde. As LPP podem ocorrer em um curto espaço de tempo, dependendo do estado clínico do paciente, podem ocorrer em até duas horas ou em menos tempo. Cerca de $95 \%$ se desenvolvem na região sacra, trocânteres e calcâneos. Embora exista essa 
frequência nessas localizações de proeminência ósseas as lesões podem se formar, independentemente da localização, basta que haja a compressão e cause isquemia e hipóxia no tecido (Severo et al., 2020).

As lesões de pele em RN possuem importância para a saúde pública, especialmente no contexto hospitalar. Sabe-se que, são uma das principais causas de prolongamento das internações dos neonatos, observando-se em média o prolongamento de 37,2 dias nas internações. Nesse contexto, a qualificação da assistência prestada pela equipe multiprofissional e a redução da morbimortalidade neonatal demandam ações específicas na prestação de cuidados peculiares ao recém-nascido, que devem ser desenvolvidos de forma integral. Esse é um elemento básico para maior racionalidade e efetividade no processo de organização da atenção perinatal (Teófilo et al., 2018).

Devido à vulnerabilidade da pele dos neonatos, a ocorrência de lesões é comum. $\mathrm{O}$ cuidado com os RN's em uma Unidade de Terapia Intensiva Neonatal deve ser intenso e vígil, pois existe uma série de fatores de risco para integridade da pele prejudicada, como punção venosa, uso de esparadrapo para fixação de cateter de oxigênio e sondas, troca de eletrodos com frequência, inexistência de mudança de decúbito na frequência correta. A manutenção da integridade da pele do RN constitui motivo de preocupação para os cuidadores na UTIN uma vez que as lesões de pele predispõem esse cliente ao risco de infecções, podendo ainda causar sequelas, cicatrizes e até mesmo aumentar tempo de internação (Sousa et al., 2011).

Além disso, a internação em Unidade Neonatal e os variados procedimentos e manuseios necessários para o cuidado do neonato o expõe a riscos para lesões de pele e infecções, contribuindo consideravelmente para o aumento da morbimortalidade desta população. Neste cenário, destacam-se as lesões por pressão, cisalhamento, lacerações, traumas, queimaduras, irritantes químicos, extravasamento de drogas, incontinência e infecções, como as que mais comumente ocorrem. Desta forma, a manutenção da integridade da pele do recém-nascido, apesar de ser um desafio para os profissionais que atuam em UN, deve ser priorizada durante o cuidado, pois contribui para o aumento das chances de sobrevivência destes pacientes. Entretanto, para que propostas de cuidado para a manutenção da integridade da pele sejam desenvolvidas, implementadas e continuadas, deve haver participação de toda a equipe multiprofissional. Uma nova prática pode ser vislumbrada quando a equipe reconhece o cuidado adequado no que se refere à manipulação do RN e sua pele e o limite de cada intervenção (Santos, \& Costa, 2015).

A UN é considerada uma área complexa dentro dos serviços de saúde, pois os neonatos estão expostos a maiores riscos devido a particularidades como sua instabilidade fisiológica e sistemas orgânicos que ainda estão em desenvolvimento, tornando a assistência oferecida nesta unidade um motivo constante de preocupação. Os eventos adversos relacionados à assistência aos neonatos internados podem ocasionar sequelas irreversíveis ao bebê, como o agravamento clínico e até a morte, sendo os mais frequentes relacionados aos distúrbios de termorregulação, glicemia, dosagem incorreta de medicação, perda acidental de cateter intravascular, lesão cutânea e infecção. Neste mesmo sentido, a segurança dos neonatos perpassa por cuidados livres de danos, que visam à manutenção e restauração da estabilidade fisiológica na adaptação extrauterina, além da necessidade de se reduzir as infecções, morbidade e mortalidade destes pacientes (Tomazoni et al., 2017)

A Unidade de Terapia Intensiva Neonatal é cenário repleto de equipamentos e rico em tecnologia. Nesta unidade, são muitos os profissionais envolvidos nos cuidados, sobretudo porque a dinâmica da UTIN é dominada por contínuos movimentos e intervenções. Neste ambiente se encontram os bebês, com seus inúmeros problemas. Alguns pesam menos de um quilo e todos requerem cuidados especiais. Para mantê-los aquecidos, precisa-se de incubadoras; para evitar asfixia, exigese oxigênio; para alimentá-los, necessita-se de sondas ou cateteres. Apesar de todas as dificuldades, a evolução da tecnologia modificou o prognóstico e a sobrevida dos bebês (Rolim et al., 2008).

Nesse local peculiar, voltado ao atendimento de pacientes graves, a prática profissional desperta reflexões. Cuidar do recém-nascido de forma humana e individualizada envolve muito mais do que conhecimentos e habilidades técnicas. Saber cuidar é abrangente, envolve o toque, o manuseio, a interação e comunicação com o bebê, requer manter a UTIN em condições 
físicas e ambientais adequadas, no intuito de oferecer melhores perspectivas de sobrevivência a estes bebês (Rolim et al., 2008).

Assim, a enfermagem percebe o RN não como objeto, mas como sujeito ativo e receptivo do cuidado, independente da sua idade ao nascimento. Sente-o capaz de interagir com ela e expressar suas emoções, o prazer, a dor, de buscar contato ou evitá-lo, quando não pode mais suportar a estimulação negativa e o estresse por ela provocado. Sob essa linha de pensamento, conforme compreendemos, é impossível fragmentar o ser humano e cuidar só do seu corpo ou apenas da sua mente, porque um aspecto influencia o outro o tempo todo, e ambos compõem uma unidade (Rolim et al., 2008).

Diante da problemática em discussão, surge como questão norteadora do estudo: "Qual a assistência de enfermagem na prevenção de lesões de pele em recém-nascidos na Unidade de Terapia Intensiva Neonatal"? Assim, o objetivo do estudo é analisar as evidências científicas sobre os cuidados de enfermagem na prevenção de lesões de pele em recém-nascidos na Unidade de Terapia Intensiva Neonatal.

A realização do estudo relacionado à temática, é essencial para a construção do conhecimento, pois, o estudo possibilita a sociedade acadêmica e cientifica a ampliar o conhecimento sobre a assistência de enfermagem na prevenção de lesões de pele em recém-nascidos na Unidade de Terapia Intensiva Neonatal. Desse modo, o estudo trará contribuições importantes para a comunidade científica e para a sociedade, na medida em que acrescentará as evidências científicas discussões relevantes a respeito dessa temática.

\section{Metodologia}

O presente estudo trata de uma revisão bibliográfica do método revisão integrativa da literatura, realizado nos meses entre agosto e dezembro de 2020. Sendo uma ferramenta de investigação que permite à procura, a avaliação crítica e a síntese das evidências disponíveis sobre o tema investigado, em que o produto final é o estado do conhecimento, a implementação de intervenções efetivas na prestação de cuidados e na redução de custos. Além disso, permite a identificação de fragilidades, que poderão conduzir ao desenvolvimento de futuras investigações (Sousa, Marques-Vieira, Severino, \& Antunes, 2017).

A revisão configura-se, portanto, como um tipo de revisão da literatura que reúne achados de estudos desenvolvidos mediante diferentes metodologias, permitindo aos revisores sintetizar resultados sem ferir a filiação epistemológica dos estudos empíricos incluídos. Para que esse processo concretize-se de maneira lógica, isenta de desatinos epistemológicos, a revisão requer que os revisores procedam à análise e à síntese dos dados primários de forma sistemática e rigorosa (Soares et al., 2014).

Esse instrumento de estudo requer um padrão de excelência quanto ao rigor metodológico para que seu produto possa trazer contribuições significativas para a ciência e para a prática clínica. A preservação deste padrão requer o uso de métodos que garantam a análise precisa, objetiva e completa do tema revisado; o suporte teórico para analisar resultados, métodos, sujeitos e variáveis dos estudos primários; a provisão de todas as informações contidas nos estudos revisados e não apenas os principais resultados, de modo a informar o leitor sem o sobrecarregar com informações desnecessárias (Soares et al., 2014).

O processo de revisão da literatura requer a elaboração de uma síntese pautada em diferentes tópicos, capazes de criar uma ampla compreensão sobre o conhecimento. A revisão da literatura é um primeiro passo para a construção do conhecimento científico, pois é através desse processo que novas teorias surgem, bem como são reconhecidas lacunas e oportunidades para o surgimento de pesquisas num assunto específico (Botelho, Cunha, \& Macedo, 2011).

A revisão integrativa permite que o leitor reconheça os profissionais que mais investigam determinado assunto, separar o achado científico de opiniões e ideias, além de descrever o conhecimento no seu estado atual, promovendo impacto sobre a prática clínica. Este método de pesquisa proporciona aos profissionais de saúde dados relevantes de um determinado assunto, em diferentes lugares e momentos, mantendo-os atualizados e facilitando as mudanças na prática clínica como 
consequência da pesquisa. Dessa forma, acreditamos que a revisão integrativa é uma ferramenta importante no processo de comunicação dos resultados de pesquisas, facilitando a utilização desses na prática clínica, uma vez que proporciona uma síntese do conhecimento já produzido e fornece subsídios para a melhoria da assistência à saúde (Mendes, Silveira, \& Galvão, 2008).

Fluxograma 1. Fases distintas da revisão integrativa.

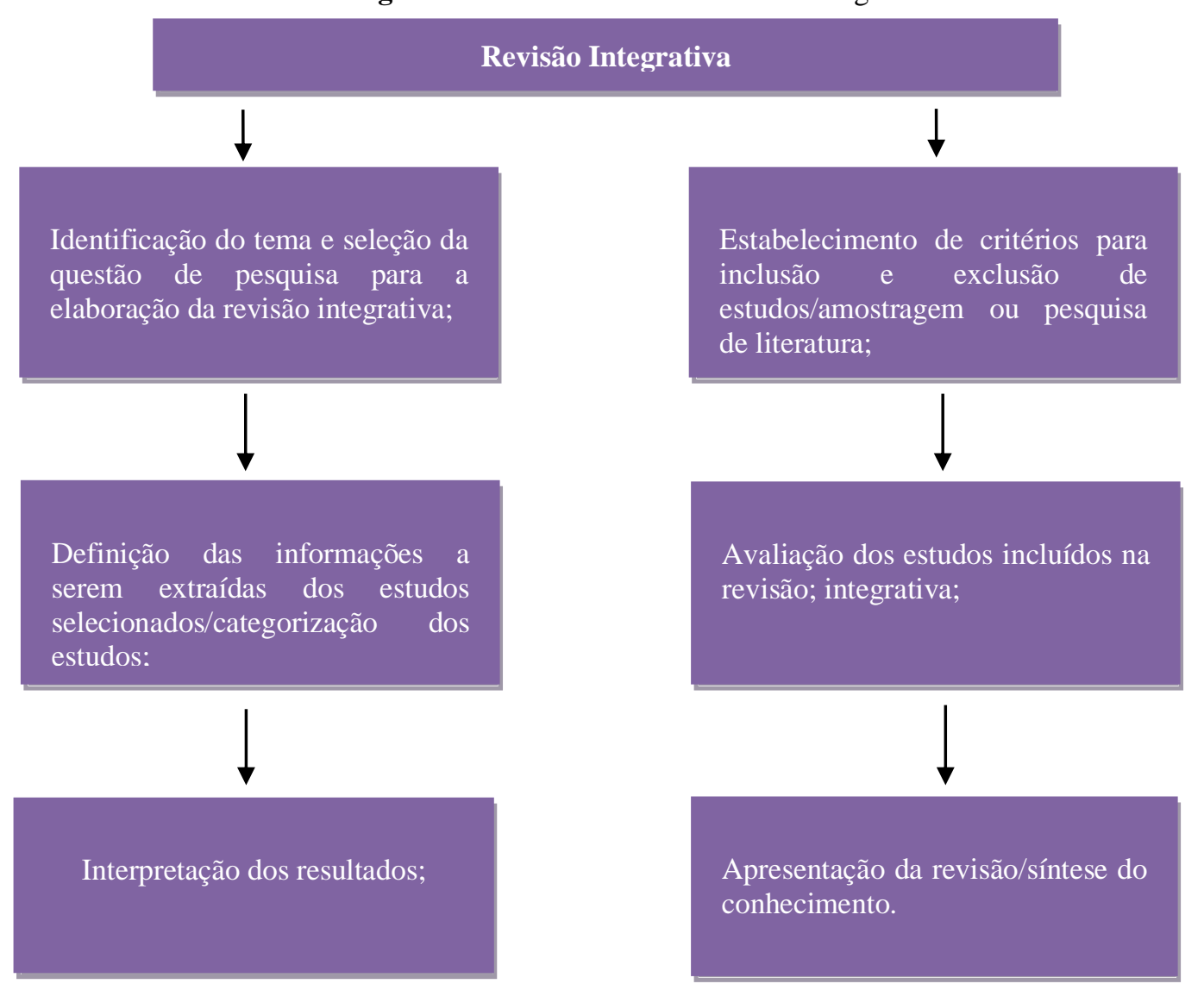

Fonte: Mendes, Silveira, \& Galvão (2008).

A revisão integrativa é um tipo de pesquisa que fornece informações mais amplas de maneira sistemática, ordenada e abrangente, sobre um assunto ou tema, com a finalidade de sintetizar resultados obtidos em pesquisa sobre temas ou questões. A definição das informações a serem extraídas dos estudos selecionados por categorização; avaliação dos estudos incluídos; interpretação dos resultados; e apresentação da revisão/síntese do conhecimento (Ercole, Melo, \& Alcoforado, 2015).

Estudo elaborado com abordagem qualitativa tornando-se importante a interpretação por parte do pesquisador com suas opiniões sobre o fenômeno em estudo. Neste tipo de pesquisa destacam-se algumas características como: a pesquisa qualitativa, em geral, ocorre no ambiente natural com coleta direta de dados e o pesquisador é o principal instrumento; os dados coletados são preferencialmente descritivos; a preocupação do processo é predominante em relação à do produto; a análise de dados e informações tende a seguir um processo indutivo (Pereira, Shitsuka, Parreira, \& Shitsuka, 2018).

De acordo com Souza, Silva, e Carvalho (2010), a ser realizada nas seguintes etapas: 1- Elaboração da pergunta norteadora; 2- Busca nas bases de dados e amostragem; 3- Coleta de dados, 4- Análise crítica.

Para responder à questão norteadora do estudo: "Qual a assistência de enfermagem na prevenção de lesões de pele em recém-nascidos na Unidade de Terapia Intensiva Neonatal”? Aplicou-se a estratégia de busca PICo utilizando os acrônimos: P - 
"Recém-nascido", "Unidades de Terapia Intensiva Neonatal", I - "Cuidados de Enfermagem", Co - "Desenluvamentos Cutâneos.”

A busca efetuou-se, através da Plataforma da Biblioteca Virtual em Saúde - BVS, utilizando as bases de dados Literatura Latino-Americana e do Caribe em Ciências da Saúde (LILACS), Base de Dados de Enfermagem (BDENF), Medical Literature Analysis and Retrieval System Online (MEDLINE) Índice Bibliográfico Español en Ciencias de la Salud (IBECS), e por meio do Portal Google Acadêmico, aderindo-se através dos descritores/palavras chaves: "Recém-nascidos", "Unidades de Terapia Intensiva Neonatal", “Cuidados de Enfermagem”, "Desenluvamentos Cutâneos”, cruzados com o operador booleando "OR" e posteriormente combinados com o operador booleano "AND".

Os critérios de inclusão estabelecidos foram: artigos originais disponibilizados na íntegra, completos, que abrangessem a temática e na forma online, publicados nos idioma português, inglês e espanhol. Os critérios de exclusão estabelecidos na seleção foram: artigos incompletos, artigos duplicados, teses, dissertações, monografias e manuais. No início da pesquisa obteve-se 12606 publicações, após a aplicação dos critérios de inclusão e exclusão totalizou-se parcialmente 4401 artigos, depois de uma leitura mais precisa aderiu-se um total final de 16 publicações de acordo para serem trabalhadas no estudo.

No Quadro 1, ilustrado abaixo, descreve a estratégia de busca utilizada pelos autores, no sentido de buscar artigos que respondessem a questão norteadora do estudo e que fossem selecionados para serem utilizados na construção do referido estudo. Sendo que no mesmo, contém o acrônimo PICo, os descritores DeCS/MeSH, os operadores booleanos "OR" e "AND" os números com o total geral e final de artigos encontrados para serem trabalhados na elaboração do presente estudo.

Quadro 1. Termos da Estratégia de Busca, Bases de Dados, 2020.

\begin{tabular}{|c|c|c|c|c|}
\hline Acrônimo & $\begin{array}{c}\text { DeCS/MeSH } \\
\text { "OR" }\end{array}$ & $\begin{array}{c}\text { DeCS/MeSH } \\
\text { "AND" }\end{array}$ & Total Geral & Total Final \\
\hline $\mathrm{P}$ & $\begin{array}{l}\text { ("Recém-Nascido") OR ("Unidade de Terapia } \\
\text { Intensiva") OR ("Unidades de Terapia } \\
\text { Intensiva Neonatal") OR ("Infant, Newborn") } \\
\text { OR ("Recién Nacido") OR ("Intensive Care } \\
\text { Units") OR ("Unidades de Cuidados } \\
\text { Intensivos") OR ("Intensive Care Units, } \\
\text { Neonatal") OR ("Unidades de Cuidado } \\
\text { Intensivo Neonatal") OR ("Criança Recém- } \\
\text { Nascida") OR ("Crianças Recém-Nascidas") } \\
\text { OR ("Lactente Recém-Nascido") OR } \\
\text { ("Lactentes Recém-Nascidos") OR (Neonato) } \\
\text { OR (Neonatos) OR ("Recém-Nascido (RN)") } \\
\text { OR ("Recém-Nascidos") OR (CTI) OR ("CTI } \\
\text { Neonatal") OR (UTI Neonatal") OR } \\
\text { ("Unidades de Terapia Intensiva para Recém- } \\
\text { Nascidos") OR ("Unidade Neonatal de } \\
\text { Cuidados Intensivos") OR ("Unidade de } \\
\text { Tratamento Intensivo Neonatal"). }\end{array}$ & $\begin{array}{l}\text { (("Recém-Nascido") OR ("Unidade de Terapia } \\
\text { Intensiva") OR ("Unidades de Terapia } \\
\text { Intensiva Neonatal") OR ("Infant, Newborn") } \\
\text { OR ("Recién Nacido") OR ("Intensive Care } \\
\text { Units") OR ("Unidades de Cuidados } \\
\text { Intensivos") OR ("Intensive Care Units, } \\
\text { Neonatal") OR ("Unidades de Cuidado } \\
\text { Intensivo Neonatal") OR ("Criança Recém- } \\
\text { Nascida") OR ("Crianças Recém-Nascidas") } \\
\text { OR ("Lactente Recém-Nascido") OR } \\
\text { ("Lactentes Recém-Nascidos") OR (Neonato) } \\
\text { OR (Neonatos) OR ("Recém-Nascido (RN)") } \\
\text { OR ("Recém-Nascidos") OR (CTI) OR ("CTI } \\
\text { Neonatal") OR (UTI Neonatal") OR } \\
\text { ("Unidades de Terapia Intensiva para Recém- } \\
\text { Nascidos") OR ("Unidade Neonatal de } \\
\text { Cuidados Intensivos") OR ("Unidade de } \\
\text { Tratamento Intensivo Neonatal")) AND }\end{array}$ & 924094 & 9796 \\
\hline I & $\begin{array}{lccr}\text { (Enfermagem) } & \text { OR } & \text { ("Atendimento } & \text { de } \\
\text { Enfermagem") } \text { OR ("Cuidado } & \text { de } \\
\text { Enfermagem") OR ("Cuidados } & \text { de } \\
\text { Enfermagem") OR (Nursing Care) } & \text { OR } \\
\text { ("Atención de Enfermería") OR (Nursing) OR } \\
\text { (Enfermería) OR ("Atención de enfermerira") } \\
\text { OR ("Assistência de Enfermagem") } & \text { OR } \\
\text { ("Atendimento de Enfermagem") } & \text { OR } \\
\text { ("Cuidado de Enfermagem"). } & \end{array}$ & $\begin{array}{lccr}\text { ((Enfermagem) } & \text { OR ("Atendimento } & \text { de } \\
\text { Enfermagem") } & \text { OR ("Cuidado } & \text { de } \\
\text { Enfermagem") } \text { OR ("Cuidados } & \text { de } \\
\text { Enfermagem") OR (Nursing Care) } & \text { OR } \\
\text { ("Atención de Enfermería") OR (Nursing) OR } \\
\text { (Enfermería) OR ("Atención de enfermeira") } \\
\text { OR ("Assistência de Enfermagem") } & \text { OR } \\
\text { ("Atendimento de Enfermagem") } & \text { OR } \\
\text { ("Cuidado de Enfermagem")) } & \text { AND }\end{array}$ & 746309 & 3840 \\
\hline Co & $\begin{array}{l}\text { ("Prevenção e controle") OR (Pele) OR } \\
\text { ("Ferimentos e Lesões") OR ("Prevention e } \\
\text { control") OR ("Prevención e control") OR } \\
\text { (Skin) OR (Piel) OR ("Wounds and Injuries") } \\
\text { OR ("Heridas y Traumatismos") OR } \\
\text { (Controle) OR (Profilaxia) OR ("Terapia } \\
\text { preventiva") OR (Lesão) OR (Lesões) OR } \\
\text { ("Medidas preventivas"). }\end{array}$ & $\begin{array}{l}\text { (("Prevenção e controle") OR (Pele) OR } \\
\text { ("Ferimentos e Lesões") OR ("Prevention e } \\
\text { control") OR ("Prevención e control") OR } \\
\text { (Skin) OR (Piel) OR ("Wounds and Injuries") } \\
\text { OR ("Heridas y Traumatismos") OR } \\
\text { (Controle) OR (Profilaxia) OR ("Terapia } \\
\text { preventiva") OR (Lesão) OR (Lesões) OR } \\
\text { ("Medidas preventivas")) }\end{array}$ & 4729854 & 5 \\
\hline
\end{tabular}




\begin{tabular}{|c|c|c|c|c|}
\hline $\begin{array}{c}\text { Google } \\
\text { Acadêmico }\end{array}$ & $\begin{array}{l}\text { "Recém-nascido" OR "Unidades de Terapia } \\
\text { Intensiva Neonatal" OR "Cuidados de } \\
\text { Enfermagem" OR "Desenluvamentos } \\
\text { Cutâneos." }\end{array}$ & $\begin{array}{l}\text { "Recém-nascido" AND "Unidades de Terapia } \\
\text { Intensiva Neonatal" AND "Cuidados de } \\
\text { Enfermagem" AND "Desenluvamentos } \\
\text { Cutâneos". }\end{array}$ & $\begin{array}{l}\text { AI: } 2810 \\
\text { AP: } 561 \\
\text { AF: } 11\end{array}$ & $\begin{array}{c}\text { Total Final } \\
\mathbf{1 6}\end{array}$ \\
\hline
\end{tabular}

Fonte: Autores (2020).

O fluxograma representado abaixo, caracteriza a estratégia de coleta de dados utilizada pelos autores, no sentido de detalhar as principais evidencias encontradas no estudo.

Fluxograma 2. Estratégia de Busca - Bases de Dados, Teresina-PI, Brasil, 2020.

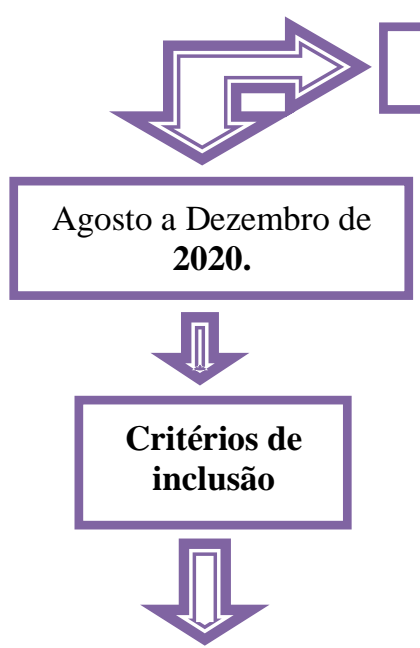

Artigos originais disponibilizados na íntegra, completos, que abrangessem a temática e na forma online, publicados nos idioma português, inglês e espanhol.
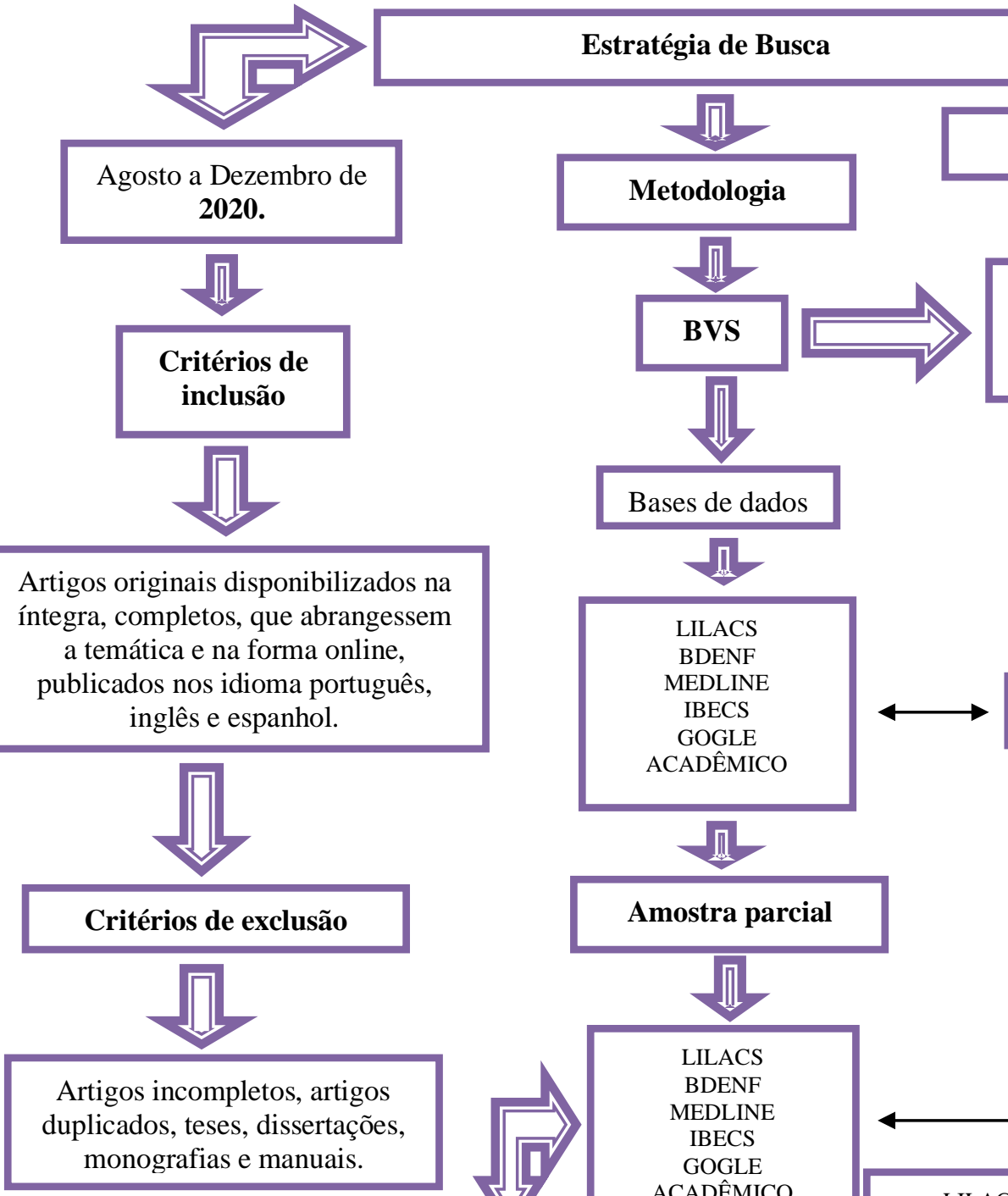

Descritores/Palavras chaves:

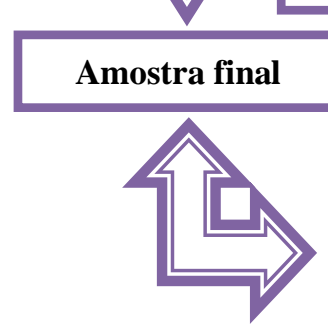

Bases de dados

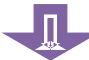

LILACS

BDENF

MEDLINE

IBECS

GOGLE

ACADÊMICO

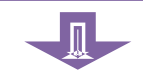

Amostra parcial

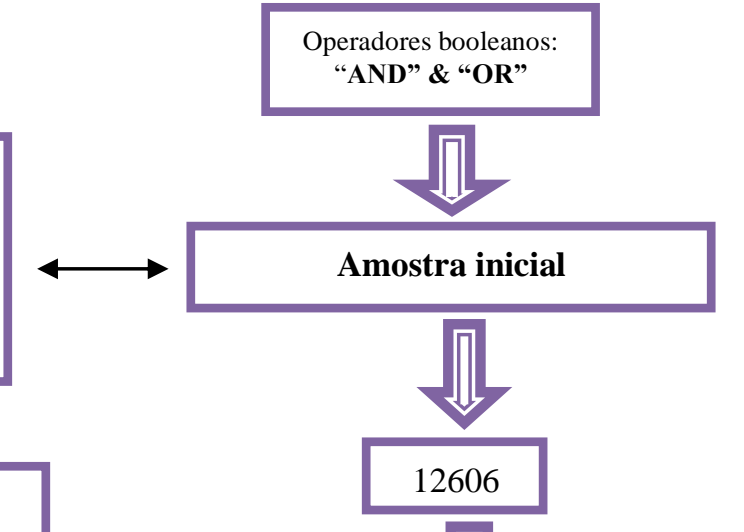

"Recém-nascidos", "Unidades de Terapia Intensiva Neonatal", "Cuidados de Enfermagem", "Desenluvamentos Cutâneos". 
estudo.

O presente estudo assegura os aspectos éticos, garantindo a autoria dos artigos pesquisados, utilizando para as citações e referências dos autores as normas APA. Os preceitos éticos estabelecidos no que se refere a zelar pela legitimidade das informações, privacidade e sigilo das informações, quando necessárias, tornando os resultados desta pesquisa públicos. Os pesquisadores buscaram a legitimidade e fidelidade nas citações dos autores seja nas citações diretas ou parafraseadas no estudo.

\section{Resultados e Discussão}

Diante dos resultados obtidos no estudo por meio da estratégia de busca, os autores delinearam variáveis para melhor descrever as evidências encontradas na pesquisa. O quadro a seguir caracteriza os artigos com base nas variáveis propostas: número do artigo, periódico, autor e ano de publicação, título, objetivo, resultados em evidências e conclusões importantes.

Quadro 2. Artigos selecionados para o estudo.

\begin{tabular}{|c|c|c|c|c|c|}
\hline $\mathbf{N}$ & Periódico & Título & $\begin{array}{l}\text { Autor e } \\
\text { ano }\end{array}$ & Objetivo & $\begin{array}{l}\text { Resultados em evidências e } \\
\text { conclusões importantes }\end{array}$ \\
\hline 1 & $\begin{array}{l}\text { Rev Enferm } \\
\text { UERJ. }\end{array}$ & $\begin{array}{l}\text { Os pais como pilares } \\
\text { para a segurança do } \\
\text { paciente em unidade } \\
\text { neonatal. }\end{array}$ & $\begin{array}{l}\text { Moura, } \\
\text { Moura, } \\
\text { Wegner, \& } \\
\text { Hoffmeister } \\
\quad, 2020 .\end{array}$ & $\begin{array}{lrr}\text { Conhecer a } & \text { experiência } & \text { dos } \\
\text { pais como estratégia } & \text { de } \\
\text { avaliação da } & \text { qualidade } & \text { da } \\
\text { assistência de enfermagem. } & \end{array}$ & $\begin{array}{l}\text { Destaca-se, no âmbito dos cuidados prestados em } \\
\text { unidades neonatais, a equipe de enfermagem, por ser } \\
\text { a equipe mais próxima do paciente, que oferece } \\
\text { assistência ao mesmo e a sua família durante } 24 \text { horas } \\
\text { e está envolvida com todos os aspectos que } \\
\text { circundam a internação hospitalar. Assim, } \\
\text { considerando que a presença dos pais na unidade } \\
\text { neonatal é um contribuinte para a segurança do } \\
\text { paciente, o objetivo deste estudo é conhecer a } \\
\text { experiência dos pais como estratégia de avaliação da } \\
\text { qualidade da assistência de enfermagem em uma } \\
\text { Unidade Neonatal. }\end{array}$ \\
\hline 2 & $\begin{array}{l}\text { Revista } \\
\text { RENE }\end{array}$ & $\begin{array}{l}\text { Escalas para } \\
\text { prevenção de lesão } \\
\text { por pressão em } \\
\text { Unidades de Terapia } \\
\text { Intensiva. }\end{array}$ & $\begin{array}{l}\text { Almeida, } \\
\text { Garces, } \\
\text { Oliveira, \& } \\
\text { Moreira, } \\
2020 .\end{array}$ & $\begin{array}{l}\text { Descrever os elementos } \\
\text { constitutivos do cuidado de } \\
\text { enfermagem presentes nas } \\
\text { escalas de avaliação do risco de } \\
\text { lesão por pressão usadas em } \\
\text { Unidades de Terapia Intensiva. }\end{array}$ & $\begin{array}{l}\text { A prevenção de lesões relacionadas às incontinências, } \\
\text { avaliação nutricional, intervenções nutricionais com o } \\
\text { objetivo de prevenir lesões e os cuidados relacionados } \\
\text { a dispositivos médicos são elementos constitutivos do } \\
\text { cuidado de enfermagem pouco explorados ou } \\
\text { ausentes nas escalas avaliadas. }\end{array}$ \\
\hline 3 & $\begin{array}{l}\text { Rev Enferm } \\
\text { UFPE Online. }\end{array}$ & $\begin{array}{lr}\text { Cuidado } & \text { e } \\
\text { manutenção } & \text { da } \\
\text { integridade } & \text { da pele } \\
\text { do } & \text { neonato } \\
\text { prematuro. } & \end{array}$ & $\begin{array}{l}\text { Chaves, } \\
\text { Santos, } \\
\text { Ataíde, \& } \\
\text { Cunha, } \\
2019 .\end{array}$ & $\begin{array}{l}\text { Descrever o cuidado de } \\
\text { Enfermagem na manutenção da } \\
\text { integridade da pele do recém- } \\
\text { nascido prematuro dentro de } \\
\text { uma Unidade de Terapia } \\
\text { Intensiva Neonatal (UTIN). }\end{array}$ & $\begin{array}{l}\text { Deve-se o cuidado com a pele do RN ser prioritário, } \\
\text { contínuo e dinâmico, durante toda a sua permanência } \\
\text { na unidade, quer seja no cuidado direto ou indireto } \\
\text { com o cliente. Torna-se fundamental, para assegurar } \\
\text { uma assistência adequada de Enfermagem ao } \\
\text { neonato, atender a necessidades como nutrição, } \\
\text { higiene, mudança de decúbito, medicações e } \\
\text { estimulação, que requerem contato direto e contínuo, } \\
\text { as quais estão imbricadas ao cuidado primordial da } \\
\text { pele. }\end{array}$ \\
\hline 4 & $\begin{array}{l}\text { Rev. Eletr. } \\
\text { Enf. }\end{array}$ & $\begin{array}{l}\text { Cuidados com a pele } \\
\text { do recém-nascido } \\
\text { prematuro. }\end{array}$ & $\begin{array}{l}\text { Aredes, } \\
\text { Santos, \& } \\
\text { Fonseca, } \\
2017 .\end{array}$ & $\begin{array}{l}\text { Descrever e analisar as } \\
\text { evidências científicas, em } \\
\text { estudos nacionais e } \\
\text { internacionais, sobre os } \\
\text { cuidados de enfermagem para } \\
\text { integridade da pele do recém- } \\
\text { nascido pré-termo na Unidade } \\
\text { de Terapia Intensiva Neonatal. }\end{array}$ & $\begin{array}{l}\text { O cuidado com a pele do RNPT é prioridade na } \\
\text { enfermagem objetivando a manutenção, prevenção e } \\
\text { recuperação da sua integridade. Esse cuidado deve } \\
\text { acontecer de maneira dinâmica, contínua, acolhedora } \\
\text { e individualizada em todos os ambientes. Para isso, o } \\
\text { enfermeiro neonatal deve conhecer as características } \\
\text { e especificidades da pele do RNPT e condições } \\
\text { ambientais que predispõem à lesão, tais como os } \\
\text { mecanismos envolvidos, a fisiologia da cicatrização, } \\
\text { os produtos indicados para prematuros e práticas de } \\
\text { cuidado baseadas nas melhores evidências. }\end{array}$ \\
\hline 5 & $\begin{array}{l}\text { J Res } \\
\text { Fundam. } \\
\text { Cuidado } \\
\text { Online. }\end{array}$ & $\begin{array}{l}\text { Cuidados com a pele } \\
\text { do recém-nascido } \\
\text { internado em } \\
\text { Unidade de Terapia } \\
\text { Intensiva Neonatal. }\end{array}$ & $\begin{array}{l}\text { Schaefer, } \\
\text { Naidom, \& } \\
\text { Neves, } \\
2016 .\end{array}$ & $\begin{array}{l}\text { Descrever a natureza e o } \\
\text { desenvolvimento dos cuidados } \\
\text { com a pele do recém-nascido". }\end{array}$ & $\begin{array}{l}\text { Diante de tantos procedimentos e manipulações } \\
\text { realizados na UTIN, manter a integridade da pele é } \\
\text { um desafio para todos os profissionais da equipe de } \\
\text { saúde, principalmente os enfermeiros que têm contato } \\
\text { direto com o RN. Portanto, é imprescindível que o } \\
\text { enfermeiro acompanhe as condições da pele do RN, } \\
\text { prestando um cuidado seguro e único a essa } \\
\text { minúscula cliente }\end{array}$ \\
\hline
\end{tabular}




\begin{tabular}{|c|c|c|c|c|c|}
\hline 6 & $\begin{array}{l}\text { R Pesq Cuid } \\
\text { Fundam } \\
\text { Online. }\end{array}$ & $\begin{array}{l}\text { O cuidado de } \\
\text { enfermagem com a } \\
\text { pele do recém- } \\
\text { nascido na Unidade } \\
\text { de Terapia Intensiva } \\
\text { Neonatal. }\end{array}$ & $\begin{array}{l}\text { Sousa et } \\
\text { al., } 2011 .\end{array}$ & $\begin{array}{l}\text { Descrever o cuidado da equipe } \\
\text { de enfermagem com a pele do } \\
\text { neonato internado na Unidade } \\
\text { de Terapia Intensiva Neonatal e } \\
\text { identificar, caso ocorram, as } \\
\text { lesões que venham a surgir na } \\
\text { pele desses RN. }\end{array}$ & $\begin{array}{l}\text { Ao se trabalhar com recém-nascidos, os profissionais } \\
\text { da saúde devem levar em consideração que se trata de } \\
\text { seres frágeis e vulneráveis, que requerem uma maior } \\
\text { atenção e cuidado por parte deles. Diante disso, a } \\
\text { proteção e preservação da pele constituem cuidados } \\
\text { indispensáveis para a saúde neonatal, e, a equipe de } \\
\text { enfermagem, por estarem mais próximas desse cliente } \\
\text { deve desenvolver a sensibilidade quanto a uma } \\
\text { prática reflexiva, voltada ao conhecimento científico } \\
\text { e ao cuidado individualizado, prestando uma } \\
\text { assistência adequada. }\end{array}$ \\
\hline 7 & $\begin{array}{c}\text { Texto } \\
\text { Contexto } \\
\text { Enferm. }\end{array}$ & \begin{tabular}{lr}
\multicolumn{2}{l}{ Prevenção de lesões } \\
de pele em recém- \\
nascidos: & o \\
conhecimento & da \\
equipe & de \\
enfermagem. &
\end{tabular} & $\begin{array}{l}\text { Santos, \& } \\
\text { Costa, } \\
2015 .\end{array}$ & $\begin{array}{l}\text { Identificar o conhecimento da } \\
\text { equipe de enfermagem sobre a } \\
\text { prevenção das lesões de pele } \\
\text { em RNs internados em UM }\end{array}$ & $\begin{array}{l}\text { O cuidado ao RN internado em UN requer exame } \\
\text { minucioso das áreas de risco, localizadas sob os } \\
\text { dispositivos. Desta forma, estas áreas devem ser } \\
\text { inspecionadas frequentemente. Além disso, o uso de } \\
\text { colchões especiais, mudança de decúbito frequente e } \\
\text { utilização de protetores sob os dispositivos são alguns } \\
\text { cuidados recomendados na prevenção de danos por } \\
\text { pressão em RN. }\end{array}$ \\
\hline 8 & $\begin{array}{l}\text { Rev RENE } \\
\text { Fortaleza. }\end{array}$ & $\begin{array}{l}\text { Cuidado com a pele } \\
\text { do recém-nascido } \\
\text { pré-termo em } \\
\text { Unidade de Terapia } \\
\text { Intensiva neonatal: } \\
\text { conhecimento da } \\
\text { enfermeira. }\end{array}$ & $\begin{array}{l}\text { Rolim et } \\
\text { al., } 2008 .\end{array}$ & $\begin{array}{l}\text { Identificar o conhecimento das } \\
\text { enfermeiras sobre técnicas de } \\
\text { prevenção de lesões na pele do } \\
\text { RNPT e verificar as possíveis } \\
\text { condutas utilizadas por estas } \\
\text { profissionais na eficácia da } \\
\text { prevenção de lesões na pele do } \\
\text { bebê. }\end{array}$ & $\begin{array}{l}\text { Entende-se que a pele do RN internado em UTIN é } \\
\text { motivo de preocupação e cuidado, por se tratar de um } \\
\text { ambiente no qual muitos procedimentos são } \\
\text { realizados e, por vezes, sem a devida atenção ao } \\
\text { número de manuseios e precauções para que a pele } \\
\text { desse bebê não sofra solução de continuidade. Estes } \\
\text { cuidados, de certo, contribuirão tanto para minimizar } \\
\text { os efeitos nocivos oriundos da hospitalização como } \\
\text { para manter a boa qualidade de sobrevida desses } \\
\text { bebês. }\end{array}$ \\
\hline 9 & Atas CIAIQ. & $\begin{array}{l}\text { Ações de prevenção } \\
\text { de lesões de pele } \\
\text { pela equipe de } \\
\text { Enfermagem em } \\
\text { Unidade de Terapia } \\
\text { Intensiva Neonata. }\end{array}$ & $\begin{array}{l}\text { Girão et al., } \\
\quad 2018 .\end{array}$ & $\begin{array}{l}\text { Analisar como a enfermagem } \\
\text { atua na prevenção de lesões de } \\
\text { pele em recém-nascidos } \\
\text { hospitalizados em UTI } \\
\text { neonatal. }\end{array}$ & $\begin{array}{l}\text { A equipe de enfermagem demonstra-se preocupação } \\
\text { acerca dos produtos que podem ser utilizados para } \\
\text { assepsia da pele do RN, cuidados necessários com as } \\
\text { fixações, uso de soluções especiais na pele do RNPT, } \\
\text { colchões adequados e mudanças frequentes de } \\
\text { decúbito, além dos cuidados durante os } \\
\text { procedimentos invasivos e uso de dispositivos para } \\
\text { prevenção de lesões nesta população. }\end{array}$ \\
\hline 10 & $\begin{array}{l}\text { Revista } \\
\text { Enfermagem } \\
\text { Atual In } \\
\text { Derme. }\end{array}$ & $\begin{array}{lr}\text { Análise } & \text { das } \\
\text { condutas } & \text { de } \\
\text { enfermagem } & \text { na } \\
\text { prevenção de lesões } \\
\text { por pressão em } \\
\text { recém-nascidos. }\end{array}$ & $\begin{array}{l}\text { Severo et } \\
\text { al., } 2020 .\end{array}$ & $\begin{array}{l}\text { Analisar as condutas da } \\
\text { enfermagem na prevenção de } \\
\text { Lesões Por Pressão (LPP) em } \\
\text { recém-nascidos em uma } \\
\text { Unidade de Terapia Intensiva } \\
\text { Neonatal (UTIN), bem como, } \\
\text { as práticas utilizadas na } \\
\text { prevenção e os fatores } \\
\text { associados as LPP. }\end{array}$ & $\begin{array}{l}\text { Evidencia-se que as práticas utilizadas pela equipe de } \\
\text { enfermagem na prevenção das lesões por pressão na } \\
\text { UTIN ocorrem mediante a mudança de decúbito, a } \\
\text { utilização do óleo de girassol, a hidratação da pele e a } \\
\text { higiene corporal. Dentre os fatores associados às } \\
\text { lesões por pressão nos recém-nascidos, destacaram a } \\
\text { pele desidratada, deixar o recém-nascido na mesma } \\
\text { posição, higiene inadequada e a utilização de } \\
\text { dispositivos. }\end{array}$ \\
\hline 11 & $\begin{array}{l}\text { REME - Rev. } \\
\text { Min. Enf. }\end{array}$ & $\begin{array}{l}\text { Lesões de pele em } \\
\text { recém-nascidos na } \\
\text { Unidade de terapia } \\
\text { intensiva neonatal e } \\
\text { a Assistência de } \\
\text { enfermagem. }\end{array}$ & $\begin{array}{c}\text { Ferreira, \& } \\
\text { Madeira, } \\
2004 .\end{array}$ & $\begin{array}{l}\text { Estudar as lesões de pele mais } \\
\text { comuns em recém-nascidos } \\
\text { internados em Unidades de } \\
\text { Terapia Intensiva Neonatal, } \\
\text { bem como suas possíveis } \\
\text { causas; Discutir à luz da } \\
\text { literatura, a atuação da equipe } \\
\text { de enfermagem em relação a } \\
\text { prevenção e tratamento das } \\
\text { lesões de pele do recém- } \\
\text { nascido (RN) Internado em } \\
\text { Unidade de Terapia Intensiva } \\
\text { Neonatal. }\end{array}$ & $\begin{array}{l}\text { Constata-se que as lesões de pele em RNs internados } \\
\text { em UTI Neonatal, em sua maioria, podem ser } \\
\text { evitadas ou minimizadas com uma adequada } \\
\text { assistência de enfermagem. Se considerarmos o } \\
\text { aspecto doloroso, esfoliante e desconfortável, o } \\
\text { aspecto estético das retrações cicatriciais e o aumento } \\
\text { da permanência desses clientes no hospital, cabe à } \\
\text { equipe de enfermagem criar medidas efetivas para } \\
\text { diminuir tais ocorrências, através de cuidados a esses } \\
\text { recém-nascidos. }\end{array}$ \\
\hline 12 & $\begin{array}{l}\text { Revista } \\
\text { Eletrônica } \\
\text { Acervo Saúde } \\
\text { / Electronic } \\
\text { Journal } \\
\text { Collection } \\
\text { Health. }\end{array}$ & $\begin{array}{l}\text { Diagnósticos } \quad \text { e } \\
\text { cuidados } \quad \text { de } \\
\text { enfermagem ao } \\
\text { recém- nascido pre- } \\
\text { maturo em Unidade } \\
\text { de Terapia Intensiva } \\
\text { Neonatal. }\end{array}$ & $\begin{array}{l}\text { Batista et } \\
\text { al., } 2019 .\end{array}$ & 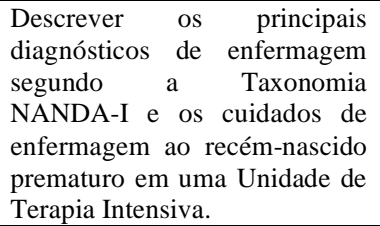 & $\begin{array}{l}\text { Os principais diagnósticos de enfermagem } \\
\text { evidenciados estavam relacionados aos riscos, como: } \\
\text { risco de infecção, risco de hipotermia e risco de } \\
\text { integridade da pele prejudicada. Os diagnósticos de } \\
\text { dor e de conforto foram pouco citados, haja vista que } \\
\text { os enfermeiros ainda tratam a dor e o conforto de } \\
\text { modo insuficiente nesse público. }\end{array}$ \\
\hline 13 & $\begin{array}{l}\text { Revista } \\
\text { Uningá } \\
\text { Review. }\end{array}$ & $\begin{array}{l}\text { Cuidados com a pele } \\
\text { do recém-nascido: } \\
\text { Um desafio para a } \\
\text { equipe da Unidade } \\
\text { de Terapia Intensiva } \\
\text { Neonatal. }\end{array}$ & $\begin{array}{l}\text { Pinto, } \\
\text { Oliveira, \& } \\
\text { Bedendo, } \\
2013 .\end{array}$ & $\begin{array}{l}\text { Identificar na produção } \\
\text { científica nacional, } \\
\text { cuidados com a pele do recém- } \\
\text { nascido. }\end{array}$ & $\begin{array}{l}\text { O cuidado com a pele do RN inclui de forma geral } \\
\text { limpeza, hidratação e manipulação adequada, não po- } \\
\text { dendo esquecer as funções sensoriais, de defesa e } \\
\text { excreção. As estratégias utilizadas devem ser bem } \\
\text { definidas e esclarecidas para toda a equipe envolvida } \\
\text { na assistência ao bebê. }\end{array}$ \\
\hline
\end{tabular}




\begin{tabular}{|c|c|c|c|c|c|}
\hline 14 & $\begin{array}{l}\text { J Res Fundam } \\
\text { Care Online. }\end{array}$ & $\begin{array}{l}\text { Cuidados com a pele } \\
\text { do recém-nascido: o } \\
\text { estado da arte. }\end{array}$ & $\begin{array}{l}\text { Santos, \& } \\
\text { Costa, } \\
2015\end{array}$ & $\begin{array}{l}\text { Conhecer o estado da arte sobre } \\
\text { os cuidados com a pele do } \\
\text { recém-nascido. }\end{array}$ & $\begin{array}{l}\text { Compreende-se que o cuidado com a pele do RN é } \\
\text { um processo amplo, que exige cientificidade, } \\
\text { responsabilidade, comprometimento, carinho e } \\
\text { dedicação por parte da equipe de enfermagem. Desta } \\
\text { forma, reforça-se a afirmação de que o cuidado com a } \\
\text { pele "é uma intervenção de enfermagem de forma } \\
\text { contínua, dinâmica, eficaz, individualizada, criteriosa } \\
\text { e humanizada, visando a promoção, manutenção ou } \\
\text { recuperação da integridade da pele do recém-nascido, } \\
\text { considerando os aspectos fisiológicos, ambientais e } \\
\text { da assistência". }\end{array}$ \\
\hline 15 & $\begin{array}{l}\text { Revista de } \\
\text { Enfermagem } \\
\text { Atual. }\end{array}$ & $\begin{array}{l}\text { Lesões de pele em } \\
\text { recém-nascido. }\end{array}$ & $\begin{array}{l}\text { Teófilo et } \\
\text { al., } 2018 .\end{array}$ & $\begin{array}{l}\text { Descrever e analisar as } \\
\text { evidências científicas acerca de } \\
\text { lesões de pele em recém- } \\
\text { nascido. }\end{array}$ & $\begin{array}{l}\text { A integridade da pele é de grande importância para a } \\
\text { sobrevida do RN. Em virtude da sua atuação entre os } \\
\text { órgãos internos e o meio externo, a pele atua como } \\
\text { barreira contra infecção. Os fatores de risco para } \\
\text { lesões de pele em RN estão associados aos } \\
\text { procedimentos realizados no atendimento hospitalar. }\end{array}$ \\
\hline 16 & $\begin{array}{l}\text { Revista } \\
\text { Brasileira de } \\
\text { Enfermagem } \\
\text { - REBEn. }\end{array}$ & $\begin{array}{l}\text { A pele do recém- } \\
\text { nascido prematuro } \\
\text { sob a avaliação do } \\
\text { enfermeiro: cuidado } \\
\text { norteando r a } \\
\text { manutenção da } \\
\text { integridade cutânea. }\end{array}$ & $\begin{array}{l}\text { Martins, \& } \\
\text { Tapia, } \\
\text { 2009. }\end{array}$ & $\begin{array}{l}\text { Agregar informações, em } \\
\text { relação ao manuseio da pele do } \\
\text { RN. }\end{array}$ & $\begin{array}{l}\text { Apresentam-se medidas relacionadas às ações e } \\
\text { atitudes do profissional, que exibe capacidade de } \\
\text { propiciar melhora no padrão de manuseio da UTIN, } \\
\text { desde a individualização do cuidado de acordo com o } \\
\text { desenvolvimento e as capacidades do RN, mantendo } \\
\text { um equilíbrio entre contenção fornecendo limites e } \\
\text { suporte para o corpo, exploração e auto organização. }\end{array}$ \\
\hline
\end{tabular}

Fonte: Autores (2020).

No Quadro 2, tem-se a apresentação dos artigos selecionados para o estudo conforme número do artigo, periódico, título, autor e ano, objetivo, resultados em evidências e conclusões importantes, com a finalidade de facilitar o desenvolvimento da discussão. A partir do estudo dos artigos estabeleceram-se discussões relevantes para observações das produções científicas relacionadas à pesquisa.

Gráfico 1. Distribuição dos artigos conforme periódico e quantidade.

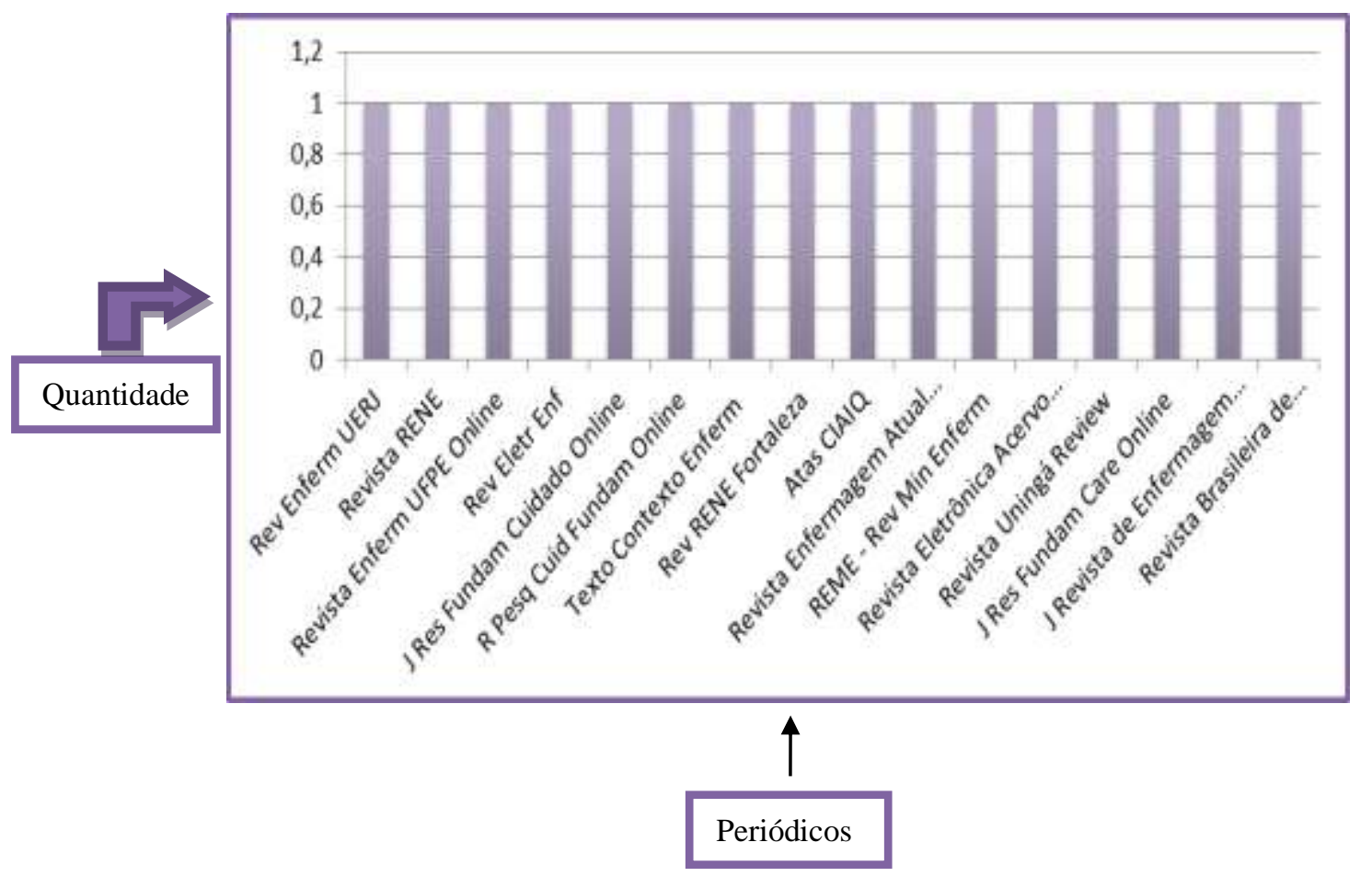

Fonte: Autores (2020).

Segundo o gráfico ilustrado acima, pode-se observar quais são os periódicos e a quantidade de artigos que foram publicados de acordo com a amostra final do referido estudo. Dessa forma, verifica-se que na Rev Enferm UERJ publicou (1), 
artigo, Revista RENE (1), Rev Enferm UFPE Online (1), Rev Eletr Enf (1), J Res Fundam Cuidado Online (1), R Pesq Cuid Fundam Online (1), Texto Contexto Enferm (1), Rev RENE Fortaleza (1), Atas CIAIQ (1), Revista Enfermagem Atual In Derme (1), REME - Rev Min Enferm (1), Revista Eletrônica Acervo Saúde/Electronic Journal Collection Heath (1), Revista Uningá Review (1), J Revista de Enfermagem Atual (1), e Revista Brasileira de Enfermagem - RENEn (1).

Gráfico 2. Distribuição dos artigos conforme os anos de publicação e quantidade.

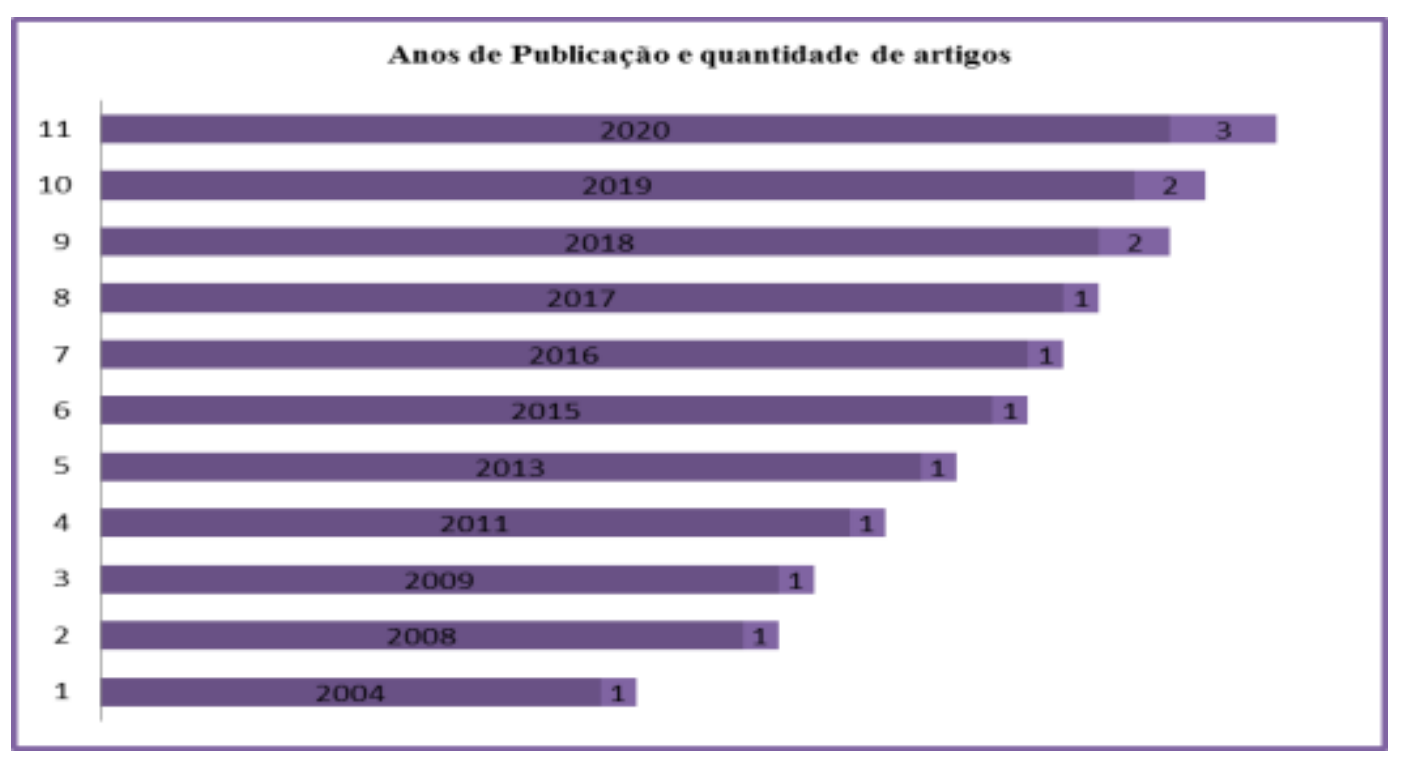

Fonte: Autores (2020).

Ao analisar o gráfico representado acima, identificam-se os anos de publicação e quantidade de artigos publicados. Nota-se que no ano de 2004 ocorreu (1) publicação, 2008 (1), 2009 (1), 2011 (1), 2013 (1), 2015 (1), 2016 (1), 2017 (1), 2018 (2), 2019 (2) e 2020 (3). Nesse sentido, levando-se ao total final de 16 artigos para comporem a construção de presente estudo.

Gráfico 3. Distribuição dos artigos conforme ano de publicação e porcentagem.

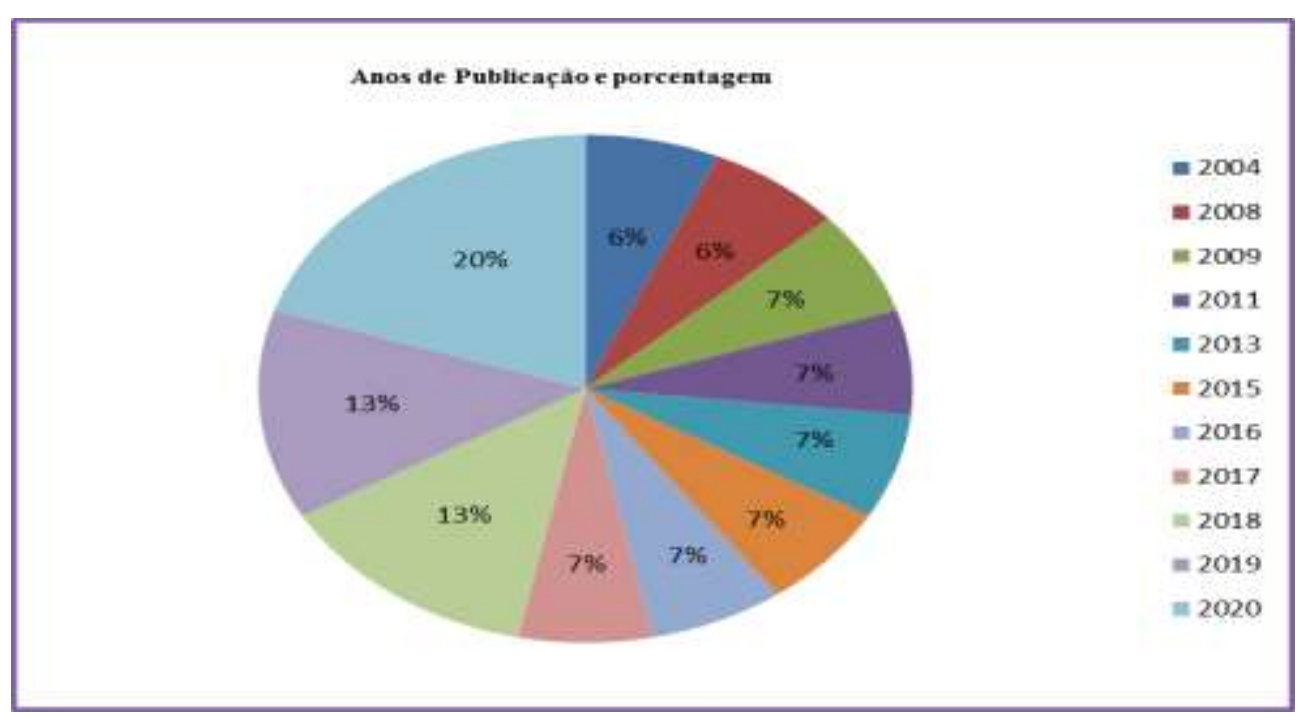

Fonte: Autores (2020). 
Diante do gráfico ilustrado acima, constata-se que no ano 2004 houve (6\%) das publicações, 2008 (6\%), 2009 (7\%), 2011 (7\%), 2013 (7\%), 2015 (7\%), 2016 (7\%), 2017 (7\%), 2018 (13\%), 2019 (13\%), e 2020 (20\%), Desse modo, alcançou-se um total geral de 16 artigos (100\%), para serem trabalhados na elaboração do presente estudo. Sendo que na seleção dos estudos sucedeu-se a aplicação dos critérios de inclusão elegidos nos aspectos metodológicos para composição do referido estudo.

A UTIN é um setor que dispõe de equipamentos para monitoração contínua e terapias específicas para neonatos a termo e pré-termo em condições de risco de vida, os profissionais que atuam nesta unidade se empenham para atender suas necessidades e de sua família. O enfermeiro da UTI deve estar preparado para lidar com as instabilidades hemodinâmicas de pacientes em situações críticas, sobrevivendo a condições adversas, em um ambiente de trabalho considerado árduo e que exige competências e habilidades profissionais para lidar com situações difíceis e garantir o atendimento integral e resolutivo do paciente (Batista et al., 2019).

A pele do RN deve ser foco de cuidado especial, dada sua importância na manutenção e recuperação da saúde do mesmo. A epiderme e a hipoderme do recém-nascido são delgadas, há menos corneificação e a coesão intercelular é deficiente, provocando o aparecimento de exulceração e bolhas ao menor trauma. As lesões de pele em recém-nascidos servem frequentemente como porta de entrada para microorganismos, principalmente em RNs debilitados como os assistidos em Unidade de Terapia Intensiva Neonatal. Como se percebe, a prevenção de lesões de pele em RNs internados em UTI Neonatal, bem como a assistência a essas crianças, exige uma equipe de enfermagem bem preparada, capacitada e suficientemente sensibilizada acerca da importância desses agravos à saúde do recém-nascido, foco de nossa atenção (Ferreira, \& Madeira, 2014).

O Ministério da Saúde (2018), assegura que posturar o RN em ninho de contenção proporciona conforto e previne posturas e padrões inadequados no desenvolvimento de RN. De forma geral, utiliza-se um tecido macio para confeccionar o ninho, acomodando o RN confortavelmente garantindo assim uma postura funcional, assim como a mudança de decúbito é necessária para proporcionar experiências sensórias adequadas e variadas, viabilizando, dessa forma, posturas protetoras para evitar lesões de peles, encurtamentos musculares, deformidades das cabeças, entre outros. No entanto, essa intervenção deve ser de forma suave, segura, respeitando o sono e observando os sinais vitais do RN.

Cuidar da pele do recém-nascido, tem sido um desafio para a enfermagem no que se refere à manutenção de sua integridade. Este cuidar da pele do RN implica refletir sobre como as ações de enfermagem podem contribuir para o aparecimento de lesões que trazem para o prematuro, complicações clínicas como o aumento do tempo de internação, das dificuldades na interação pais/RN, de procedimentos considerados dolorosos e da utilização de toda tecnologia disponível, cabendo ao enfermeiro neonatal, à sistematização da assistência para minimizar o aparecimento dessas lesões e a condução destes cuidados (Pinto, Oliveira, \& Bedendo, 2013).

Entre os cuidados com a pele do pré-termo em Unidade de Terapia Intensiva Neonatal, está o banho com sabonete, um procedimento rotineiro e tradicional de higiene não justificado por evidências. Atualmente, sabe-se que essa rotina de banho pode trazer prejuízos à pele, devido à fragilidade da epiderme do RN. O banho do neonato visa remover resíduos presentes na pele e reduzir sua colonização. Porém, nem sempre ele produz resultados benéficos. Os agentes químicos usados nos sabonetes podem causar irritação da pele e absorção de substâncias tóxicas; além disso, o banho pode desencadear hipotermia e desestabilizar os sinais vitais do prematuro. O cuidador do RN deve compreender o cuidado com a pele como fator preventivo de infecções, pois a pele lesada funcionada como porta de entrada para fungos e bactérias, além de que, aumenta o consumo calórico devido ao trabalho do organismo no reparo do tecido lesado (Pinto, Oliveira, \& Bedendo, 2013).

O cuidado com a pele do RN inclui de forma geral limpeza, hidratação e manipulação adequada, não podendo esquecer as funções sensoriais, de defesa e excreção. As estratégias utilizadas devem ser bem definidas e esclarecidas para toda 
a equipe envolvida na assistência ao bebê. A pele do RN passa pelo processo de adaptação ao ambiente extrauterino exigindo por parte do cuidador estratégias especiais para manutenção da integridade cutânea do bebê. Quando esse é prematuro a pele é sensível, fina e frágil devido à característica de neutralidade do $\mathrm{pH}$ na superfície corpórea, aumenta o risco de infecções por diversas cepas de microrganismos. Um passo decisivo para a saúde do RN está calcado em conceitos e estratégias para proteção/prevenção e tratamento adequado à preservação da pele do bebê (Pinto, Oliveira, \& Bedendo, 2013).

Nesse sentido, o olhar para o desenvolvimento de uma abordagem estruturada, individualizada e sistematizada para superar os desafios encontrados e ampliar os aspectos facilitadores naquilo que diz respeito ao cuidado de enfermagem direcionado à prevenção de lesões por pressão em terapia intensiva, tendo em vista que a qualidade do cuidado de enfermagem está intrinsecamente associada a uma menor incidência de lesões nas instituições que prestam assistência à saúde. Dessa forma, Ao iniciar os cuidados destinados à manutenção da integridade da pele, a avaliação estruturada do risco para o desenvolvimento de lesão por pressão deve ser realizada precocemente após admissão na Unidade de Terapia Intensiva, sendo necessária a reavaliação quando houver mudança significativa no quadro clínico do paciente (Almeida, Garces, Oliveira, \& Moreira, 2020).

A avaliação da pele será influenciada pela qualidade do exame físico realizado pelo enfermeiro, tornando tal ação fundamental para o profissional em UTIN. A técnica propedêutica da inspeção será aliada direta na busca por sinais e sintomas na pele e reconhecimento de situações que podem representar riscos para a manutenção da integridade da pele (Almeida, Garces, Oliveira, \& Moreira, 2020).

Tendo em vista serem os RNs internados em UTIN muito manuseados devido aos procedimentos necessários para o suporte da vida, pode ocorrer a quebra da membrana de proteção. Assim, os cuidados com a pele devem ser redobrados. Verifica-se que os participantes referiram ser mais importante haver a prevenção das lesões realizando inspeção periódica da pele dos RNs. Verifica-se ainda que diversas medidas poderiam ser implementadas para a prevenção de lesões na pele dos RNs, como o cuidado com as fixações, treinamento em serviço, uso de soluções especiais na pele do RNPT, colchões adequados e mudanças frequentes de decúbito, obedecendo mais os critérios da SAE. A avaliação das condições da pele do RNPT é considerada essencial no âmbito da prevenção, visto que ela desempenha um papel relevante na recuperação deste. O enfermeiro necessita avaliar as condições da pele do RN, bem como conhecer formas de manter sua integridade e tratar as lesões evitando agravos à sua saúde (Girão et al., 2018).

Sabe-se, portanto, que a equipe de enfermagem é uma das principais responsáveis pelo cuidado ao RN na UTIN. Por mais simples que possa parecer o cuidado realizado na rotina de enfermagem, desde o momento da admissão do bebê até o momento de sua alta hospitalar, o RN grave é submetido a uma série de manuseios, que podem favorecer o surgimento de lesões, devido à sua frequência repetitiva e a fragilidade da sua pele (Girão et al., 2018).

Os profissionais da equipe de enfermagem devem ter atenção redobrada no manuseio de equipamentos e dispositivos que auxiliam na recuperação dos RNs, evitando ao máximo a fixação de adesivos à pele, realizando mudanças frequentes de decúbito e, por fim, elaborando e aprimorando protocolos específicos de cuidados com a pele. A realização de uma assistência qualificada depende da capacitação de profissionais sensíveis, adquiridas por meio de suas vivências cotidianas de cuidado, da participação em programas de educação permanente em serviço e da reflexão acerca do compromisso com o seu fazer junto ao RN. Percebeu-se, também, que a adoção de protocolos assistenciais, baseados em estudos atuais e nas evidências, constitui uma importante medida na padronização de condutas, e com isso visa diminuir os riscos de aparecimento dessas lesões (Girão et al., 2018).

Compreende-se que o cuidado com a pele do RN é um processo amplo, que exige cientificidade, responsabilidade, comprometimento, carinho e dedicação por parte da equipe de enfermagem. Desta forma, reforça-se a afirmação de que o cuidado com a pele "é uma intervenção de enfermagem de forma contínua, dinâmica, eficaz, individualizada, criteriosa e 
humanizada, visando à promoção, manutenção ou recuperação da integridade da pele do recém-nascido, considerando os aspectos fisiológicos, ambientais e da assistência" (Santos, \& Costa, 2015).

As práticas de cuidados com a pele realizada diariamente nas UTIs Neonatais incluem a manutenção da temperatura e umidade do ambiente, por meio de incubadoras, o posicionamento, o banho, a lubrificação com óleos emolientes, o uso de soluções cutâneas para anti-sepsia, fixação ou remoção de adesivos para suporte à vida e aparelhos de monitorização, realização de procedimentos invasivos, como punções venosas ou arteriais. O manuseio apropriado da pele do RN denota a valorização, pelo enfermeiro e sua equipe, dos detalhes inerentes nos cuidados prestados. É uma prática desafiadora, porém bela, responsável por repercussões no sistema de vida desses recém-nascidos ou melhor, pela qualidade de vida (Martins, \& Tapia, 2009).

Tendo em vista a importância deste tegumento para a sobrevivência do prematuro, estratégias têm sido realizadas para manter a integridade da pele, para tanto, há necessidade de padronização dos cuidados de enfermagem, e que esta esteja presente na prescrição de enfermagem de cada $\mathrm{RN}$, tornando possível a individualização do cuidado prestado à pele do prematuro (Martins, \& Tapia, 2009).

No que diz respeito aos cuidados específicos de enfermagem, o objetivo da assistência é a condução do neonato à recuperação, adaptação e bem-estar, portanto, devem estar fundamentados em conhecimentos científicos e na autonomia do profissional de enfermagem. Para o enfermeiro prestar a adequada assistência, faz-se necessário um aporte de evidências científicas que o auxiliem na escolha dos melhores produtos, técnicas, materiais e procedimentos. Destaca-se a equipe de Enfermagem como principal responsável pelo manuseio dos recém-nascidos nestas unidades, e cuidados específicos desta categoria com a pele são necessários (Teófilo et al., 2018).

Acredita-se, que a Enfermagem tem, como foco, o cuidar do indivíduo e, na área neonatal, o cuidado é voltado ao recém-nascido e suas particularidades, fato de constante preocupação na Unidade de Internação Neonatal (UIN), devendo então ser primazia nas ações do enfermeiro, e a pele faz parte dessa assistência diária, já que é uma barreira protetora contra agentes externos. Constitui-se a pele do recém-nascido uma importante barreira para impedir a perda de água e manter o equilíbrio homeostático, pois, ao nascer, a pele do RN está envolta em vérnix caseoso, uma barreira lipídica que protege a pele do bebê intraútero. Torna-se o pH da pele do RN ácido e, assim, em quatro dias, está colonizada com a flora vaginal, e esta acidez faz-se necessária para protegê-lo contra patógenos agressivos. Complementa-se enfatizando que, com duas semanas de vida, a pele está completamente queratinizada e pronta para resistir à absorção de substâncias tóxicas (Chaves, Santos, Ataíde, \& Cunha, 2019).

Apresentam-se os cuidados intensivos aos recém-nascidos como manter a integridade da pele do bebê, em razão da necessidade de fixar, de maneira segura, o tubo endotraqueal, os sensores, as sondas, o cateter de infusão venosa e outros materiais sobre a pele imatura, sem causar lesões severas, uma vez que a presença de lesões representa um fator complicador no estabelecimento da saúde do neonato. Deve-se o cuidado com a pele do RN ser prioritário, contínuo e dinâmico, durante toda a sua permanência na unidade, quer seja no cuidado direto ou indireto com o cliente (Chaves, Santos, Ataíde, \& Cunha, 2019).

Torna-se fundamental, para assegurar uma assistência adequada de Enfermagem ao neonato, atender a necessidades como nutrição, higiene, mudança de decúbito, medicações e estimulação, que requerem contato direto e contínuo, as quais estão imbricadas ao cuidado primordial da pele. Averígua-se, assim, que os profissionais fazem uso de métodos para melhorar a integridade cutânea ou mesmo evitar um possível rompimento na mesma, e o uso de curativos protetores de pele à base de hidrocoloide, poliuretano, silicone, entre outros, pode ser uma alternativa tanto para proteger a pele de pressões pelo uso de dispositivos, como para prevenir lesões por remoção de adesivos. Reduz-se, por estes, o trauma, e eles devem ser colocados 
entre a pele, o dispositivo e o adesivo, proporcionando uma barreira protetora cutânea (Chaves, Santos, Ataíde, \& Cunha, 2019).

A Enfermagem está diretamente ligada à assistência do recém-nascido, sendo de grande importância na recuperação e melhoramento da saúde desse paciente na UTIN, pois seus profissionais procuram prestar uma assistência holística e de forma humanizada, respeitando as limitações do neonato, realizando os mais diversos procedimentos e fazendo uso de técnicas adequadas como a utilização de adesivos, óleos, entre outros, para realizar procedimentos necessários com destreza para evitar lesões e, assim, aumentar a fragilidade desse bebê (Chaves, Santos, Ataíde, \& Cunha, 2019).

\section{Conclusão}

Evidenciou-se no estudo, que é necessário buscar na assistência de enfermagem em UTIN, pela sua alta complexidade em atendimentos, desenvolver métodos de trabalhos relacionados ao cuidado com a pele dos RNs, que proporcione uma prática de enfermagem unificada, evidente, com metas a curto e longo prazo, favorecendo e explicitando a eficácia das atividades desenvolvidas. Consolidando assim, um cuidado de enfermagem com qualidade, passível de críticas construtivas e avaliações contínuas, o que poderia tornar a avaliação do cuidado eficaz, além de proporcionar a avaliação dos custos dessa prática.

Nesse contexto, a enfermagem tem demonstrado interesse em oferecer uma assistência especializada, voltada para o holismo, na tentativa de contribuir para a promoção da qualidade de vida destes clientes durante sua permanência nas unidades neonatais, cientes de que esta experiência repercute de maneira significativa na vida futura. O cuidado individualizado, delineado, sistematizado, aportado para uma assistência livre de negligência, norteado pela ética profissional, é um grande desafio para o enfermeiro, diante do desafio de oferecer uma assistência complexa e eficaz, mantendo a integridade da pele do neonato. Assim, os enfermeiros são os profissionais responsáveis por diversas ações essenciais para a prevenção e tratamento das lesões de pele. Estas ações devem ser individualizadas, embasadas em conhecimento científico e, principalmente, terem suas abordagens baseadas no trabalho em equipe integrado, além de acompanhamento intensivo dos recém-nascidos, a fim de evitar e/ou diminuir as lesões de pele nessa parcela da população durante sua internação nas Unidades Neonatais.

Diante desse contexto, identifica-se que a deteç̧ão precoce dos riscos de desenvolver lesões de pele e a aplicação de medidas preventivas possibilitam o aumento da qualidade de vida dos neonatos internados em UTIN, evitando injúrias cutâneas decorrentes da assistência prestada nesse ambiente. Torna-se importante a realização de estudos futuros com a finalidade de ampliar a produção científica a respeito dessa temática tão relevante, sendo de suma importância, no sentido de aprofundar discussões que possam contribuir para a promoção da saúde e na melhoria da qualidade de vida desses pacientes.

\section{Referências}

Almeida, Í. L. S. D., Garces, T. S., Oliveira, G. Y. M. D., \& Moreira, T. M. M. (2020). Escalas para prevenção de lesão por pressão em Unidades de Terapia Intensiva.

Aredes, N. D. A., Santos, R. C. A., \& Fonseca, L. M. M. Cuidados com a pele do recém-nascido prematuro. Rev Eletr Enferm [Internet]. 2017. 19: 19-59.

Batista, C. D. M., Monteiro, J. C., Pinheiro, V. R., Soares, T. B., de Lima, F. C., Nascimento, M. H. M., \& Ueno, T. M. R. L. (2019). Diagnósticos e cuidados de enfermagem ao recém-nascido prematuro em Unidade de Terapia Intensiva Neonatal. Revista Eletrônica Acervo Saúde, (35), e1593-e1593.

Botelho, L. L. R., de Almeida Cunha, C. C., \& Macedo, M. (2011). O método da revisão integrativa nos estudos organizacionais. Gestão e sociedade, 5(11), $121-136$.

Ercole, F. F., Melo, L. D., \& Alcoforado, C. L. G. C. (2014). Revisão integrativa versus revisão sistemática. Rev Min Enferm, $18(1)$, 9-12.

Feitosa Chaves, A. C., Passos Santos, A., Nogueira Ataíde, K. M., \& Bezerra Cunha, K. J. (2019). Cuidado e manutenção da inte gridade da pele do neonato prematuro. Journal of Nursing UFPE/Revista de Enfermagem UFPE, 13(2).

Ferreira, V. R., \& Madeira, L. M. (2004). Lesões de pele em recém-nascidos na unidade de terapia intensiva neonatal e a assistência de enfermagem. REME Rev. Min. Enferm, 216-222. 
Research, Society and Development, v. 10, n. 2, e20410212281, 2021

(CC BY 4.0) | ISSN 2525-3409 | DOI: http://dx.doi.org/10.33448/rsd-v10i2.12281

Girão, S. G. M., Vasconcelos, M. G. F., Sales, T. B., de Oliveira, K. R. M., de Sousa, E. M., da Costa, S. R., \& de Queiroz, A. M. (2018). Ações de prevenção de lesões de pele pela equipe de Enfermagem em Unidade de Terapia Intensiva Neonatal. CIAIQ2018, 2.

Mariga, T. I. S., Naidon, A. M., \& Tatsch, E. N. (2016). Cuidados com a pele do recém-nascido internado em unidade de terapia intensiva neonatal. Skin care to newborns admitted in neonatal intensive care unit. Revista de Pesquisa: Cuidado é Fundamental Online, 8(4), 5156-5162.

Martins, C. P., \& Tapia, C. E. V. (2009). A pele do recém-nascido prematuro sob aa avaliação do enfermeiro: cuidado norteando a manutenção da integridade cutânea. Revista Brasileira de Enfermagem, 62(5), 778-783.

Mendes, K. D. S., Silveira, R. C. D. C. P., \& Galvão, C. M. (2008). Revisão integrativa: método de pesquisa para a incorporação de evidências na saúde e na enfermagem. Texto \& contexto enfermagem, 17(4), 758-764.

Moura, L. P., de Moura, G. M. S. S., Wegner, W., \& Hoffmeister, L. V. (2020). Os pais como pilares para a segurança do paciente em unidade neonatal. Revista Enfermagem UERJ, 28, 48578.

Pereira, A. S., Shitsuka, D. M., Parreira, F. J., \& Shitsuka, R. (2018). Metodologia da pesquisa científica.

Pinto, M. C. P. F., Oliveira, M. L. F., \& Bedendo, J. (2013). Cuidados com a pele do recém-nascido: um desafio para a equipe da Unidade de Terapia Intensiva Neonatal. Revista Uningá Review, 16(1).

Rolim, K. M. C., Linhares, D. C., Rabelo, L. S., Gurgel, E. D. P. P., Magalhães, F. J., \& Caetano, J. Á. (2008). Cuidado com a pele do recém-nascido prétermo em unidade de terapia intensiva neonatal: conhecimento da enfermeira.

Santos, S. V., \& Costa, R. (2015). Cuidados com a pele do recém-nascido: o estado da arte. Revista de Pesquisa Cuidado é Fundamental Online, 7(3), 28872901.

Santos, S. V., \& Costa, R. (2015). Prevenção de lesões de pele em recém-nascidos: o conhecimento da equipe de enfermagem. Texto \& ContextoEnfermagem, 24(3), 731-739.

Severo, E. A. D. A. R., Sousa, F. D. C. A., Silva, W. C., Melo, K. C., Soares, A. N., da Silva, C. O., \& Lima, J. C. D. S. (2020). Análise das condutas de enfermagem na prevenção de lesões por pressão em recém-nascidos. Revista Enfermagem Atual In Derme, 94(32).

Soares, C. B., Hoga, L. A. K., Peduzzi, M., Sangaleti, C., Yonekura, T., \& Silva, D. R. A. D. (2014). Revisão integrativa: conceitos e métodos utilizados na enfermagem. Revista da Escola de Enfermagem da USP, 48(2), 335-345.

Sousa, A. M., Monte, E. C., Miranda, I. N., Moura, M. E. B., de Souza Monteiro, C. F., \& de Araújo, T. M. E. (2011). O cuidado de enfermagem com a pele do recém-nascido na unidade de terapia intensiva neonatal. Revista de Pesquisa Cuidado é Fundamental Online, 3, $52-62$.

Sousa, L. M. M., Marques-Vieira, C. M. A., Severino, S. S. P., \& Antunes, A. V. (2017). A metodologia de revisão integrativa da literatura em enfermagem. No21 Série 2-Novembro 2017, 17.

Souza, M. T. D., Silva, M. D. D., \& Carvalho, R. D. (2010). Revisão integrativa: o que é e como fazer. Einstein, 8(1), 102-106. 